\title{
Induction of heat, freezing and salt tolerance by heat and salt shock in Saccharomyces cerevisiae
}

\author{
J. G. Lewis, R. P. Learmonth and K. Watson \\ Author for correspondence: K. Watson. Tel: +616773 3125. Fax: +61 67728235.
}

Department of Biochemistry, Microbiology and Nutrition, University of New England, Armidale, 2351, Australia

\begin{abstract}
Stress tolerance of Saccharomyces cerevisiae was examined after exposure to heat and salt shock in the presence or absence of the protein synthesis inhibitor cycloheximide. Cells heat-shocked ( $37{ }^{\circ} \mathrm{C}$ for $45 \mathrm{~min}$ ) in the absence of cycloheximide demonstrated increased tolerance of heat, freezing and salt stress. For cells heat-shocked in the presence of cycloheximide, heat and salt tolerance could still be induced, although at lower levels, while induction of freezing tolerance was completely inhibited. These results indicated that while heat shock proteins (hsps) may contribute to induced heat and salt tolerance they are not essential, although induction of freezing tolerance appears to require protein synthesis. Exposure of cells to salt shock $(300 \mathrm{mM} \mathrm{NaCl}$ for $45 \mathrm{~min}$ ) induced stress protein synthesis and the accumulation of glycerol, responses analogous to induction of hsp synthesis and trehalose accumulation in cells exposed to heat shock. Cells salt-shocked in the absence of cycloheximide showed a similar pattern of induced stress tolerance as with heat, with increased tolerance of heat, salt and freezing. Cells salt-shocked in the presence of cycloheximide continued to show induced heat and salt tolerance, but freezing tolerance could not be induced. These results lend support to the hypothesis that hsp synthesis is not essential for induced tolerance of some forms of stress and that accumulated solutes such as trehalose or glycerol may contribute to induced stress tolerance.
\end{abstract}

Keywords: Saccharomyces cerevisiae, stress tolerance, heat shock, salt shock

\section{INTRODUCTION}

In Sacharomyces cerevisiae the heat shock response is characterized by rapid changes in cellular physiology and increased tolerance of stress conditions. Among a range of responses, which include changes in the activity of the plasma membrane ATPase and alterations in antioxidant levels (Piper, 1993), two major responses have been noted, the induction of heat shock proteins (hsps; Lindquist \& Craig, 1988) and the rapid accumulation of the disaccharide trehalose (Attfield, 1987; Hottiger et al., 1987). These two aspects of the heat shock response have been widely studied and both have been suggested to contribute substantially to the increase in stress tolerance associated with heat shock. However, while both are likely to be major factors involved in stress tolerance, the relative contribution of each and their mechanisms of

Abbreviation : hsp, heat shock protein. action are still unresolved (Watson, 1990; Craig et al., 1993; Piper, 1993).

There is strong evidence which suggests that hsps are involved in tolerance to heat stress following heat shock, and there is a good correlation between induction and decline of heat tolerance and induction and decline of heat shock proteins (McAlister \& Finkelstein, 1980; Lindquist \& Craig, 1988). In addition, there is evidence that specific hsps are associated with heat tolerance, in particular hsp104 (Sanchez \& Lindquist, 1990; Sanchez et al., 1992). However, some reports ascribe less importance to hsps in heat tolerance (Hall, 1983; Watson et al., 1984; Smith \& Yaffe, 1991), and others suggest that trehalose may be more important than hsps (Hottiger et al., 1989, 1992; De Virgilio et al., 1990, 1991). In addition, there is a growing number of researchers who believe that both mechanisms may contribute to cell survival after heat stress (Panek $e t$ al., 1990; De Virgilio et al., 1991; Hottiger et al., 1992; Piper, 1993).

A role for hsps has also been suggested in heat-shock- 
induced freezing tolerance. In S. cerevisiae, Komatsu et al. (1990) demonstrated induction of cryotolerance by heat shock and that the presence of cycloheximide during heat shock completely inhibited this response. This result may suggest that hsp synthesis is necessary for heat-shockinduced resistance to rapid freezing.

A third stress which has been studied following heat shock is exposure to high salt concentrations. In the work of Trollmo et al. (1988), S. cerevisiae cells were heatshocked and then subjected to salt stress by plating out on agar containing $1.5 \mathrm{M} \mathrm{NaCl}$. Their results showed no increase in the plate count on the salt stress agar after heat shock, implying that heat shock could not protect cells from the stress. In another study by Varela et al. (1992) yeast cells were subjected to heat shock and the salt tolerance of the cells was assayed by measuring the uptake of methionine under salt stress conditions. Uptake of methionine in cells exposed to salt stress did not recover any more quickly after heat shock than in control cells, implying that heat shock did not protect cells from the stress. From these two studies, evidence suggests that heat shock will not induce salt tolerance in $S$. cerevisiae. However, it has been demonstrated that heat shock will induce the accumulation of trehalose (Attfield, 1987; Hottiger et al., 1987) and that trehalose can have a protective effect on cells subjected to osmotic (Mackenzie et al., 1988) and dehydration stress (Hottiger et al., 1987). Consequently, heat shock induction of salt tolerance should be possible, especially in those strains of $S$. cerevisiae which accumulate significant levels of trehalose. In addition, there is one unpublished report of induction of osmotolerance in S. cerevisiae by heat shock (Singh, 1987, cited in Brown, 1990), and several reports of induction of salt tolerance by heat shock in other organisms, namely cultured tobacco plant cells (Harrington \& Alm, 1988) and Bacillus subtilis (Volker et al., 1992).

In the work presented here, physiological shock has been used to manipulate the levels of stress proteins and accumulated polyols in yeast to try to determine the relative contributions of these two factors to stress tolerance. The physiological effects of heat and salt shock are similar, in that both induce the accumulation of intracellular solutes, heat shock inducing the accumulation of trehalose (Attfield, 1987; Hottiger et al., 1987) and salt shock inducing the synthesis (and partial accumulation) of glycerol (Brown, 1990). In addition, both heat (McAlister \& Finkelstein, 1980) and salt shock (Varela et al., 1992) are able to induce the synthesis of hsps. Results indicate that induction of hsps is essential for induced tolerance to rapid freezing, but not for heat and salt stress. In the case of the latter two stresses it seems likely that induced tolerance may at least be partly explained in terms of the accumulated polyols induced by physiological shock. In addition, we report induction of salt tolerance by heat shock in yeast, a previously unreported observation.

\section{METHODS}

Yeast strains and culture conditions. $S$. cerevisiae strains $A 4$ and A9 (wild-type baking strains), SG195 (ATCC 38554), K7
(ATCC 26422) and DBY746 (ATCC 44773) were maintained on YEP agar slopes containing $0.5 \%$ yeast extract (Oxoid), $0.5 \%$ bacteriological peptone (Oxoid), $1 \%$ glucose, $0.3 \%$ $\left(\mathrm{NH}_{4}\right)_{2} \mathrm{SO}_{4}, 0.3 \% \mathrm{KH}_{2} \mathrm{PO}_{4}$ and $1 \%$ agar (all w/v). Starter cultures $(80 \mathrm{ml}$ in a $250 \mathrm{ml}$ Erlenmeyer flask) were grown overnight $\left(25^{\circ} \mathrm{C}, 180\right.$ r.p.m.) in YEP broth. Starters at this stage were in respiratory growth phase and were used to inoculate experimental cultures (1 litre YEP containing $2 \%$ glucose in a 31 Erlenmeyer flask) to an $\mathrm{OD}_{640} 0 \cdot 10$. Growth of experimental cultures was monitored by $\mathrm{OD}_{640}$ and glucose, and experiments commenced when $\mathrm{OD}_{640}$ reached $0 \cdot 60$. Cultures at this stage were in respirofermentative growth phase (Lewis $e t$ al., 1993b) and still contained at least $1 \%$ glucose. Unless otherwise stated, all experiments were repeated between three and six times and produced consistent results.

Heat and salt shock. Cells were heat shocked by rapidly raising their temperature from $25^{\circ} \mathrm{C}$ to $37^{\circ} \mathrm{C}$ in a $60^{\circ} \mathrm{C}$ water bath, then incubated in a $37^{\circ} \mathrm{C}$ water bath oscillating at 180 r.p.m. The largest culture volume heat-shocked was $300 \mathrm{ml}$ which took approximately $45 \mathrm{~s}$ to reach $37^{\circ} \mathrm{C}$. Cells were osmotically shocked by the addition of $300 \mathrm{mM} \mathrm{NaCl}$ to the culture, raising the osmolarity from approximately $250 \mathrm{mOm} \mathrm{l}^{-1}$ to $800 \mathrm{mOm} \mathrm{l}^{-1}$. Unless otherwise stated, cultures were shocked for $45 \mathrm{~min}$. Where necessary, protein synthesis was blocked by the addition of $20-50 \mu \mathrm{g}$ cycloheximide $\mathrm{ml}^{-1}, 15 \mathrm{~min}$ prior to heat or osmotic shock. Inhibition of protein synthesis was confirmed by measuring incorporation into protein of $\left[{ }^{14} \mathrm{C}\right]$ leucine and by examination of the pattern of protein synthesis revealed by polyacrylamide gel electrophoresis (see below).

Radioactive pulse labelling. A sample of $150 \mathrm{ml}$ culture was centrifuged and the pellet resuspended in $12 \mathrm{ml}$ of the supernatant. This was divided into $2 \mathrm{ml}$ samples and placed into $22 \mathrm{~mm}$ diameter stoppered test tubes in a $25^{\circ} \mathrm{C}$ oscillating water bath. Cycloheximide was added where required and cells incubated for $15 \mathrm{~min}$. Cells were heat- or osmotically shocked as required and after $5 \mathrm{~min}, \quad 50 \mu \mathrm{Ci} \quad(1 \mathrm{Ci}=37 \mathrm{GBq})$ $\left[{ }^{35} \mathrm{~S}\right]$ methionine label (trans ${ }^{35} \mathrm{~S}$ label, containing $75 \% \mathrm{~L}$ ${ }^{35}$ S $]$ methionine and $15 \% \mathrm{~L}-\left[{ }^{35} \mathrm{~S}\right]$ cysteine, $1037 \mathrm{Ci} \mathrm{mmol}^{-1}$; ICN Biomedicals) was added to each tube. Tubes were incubated for a further $30 \mathrm{~min}$ before incorporation of the label was halted by transferring samples of $1.5 \mathrm{ml}$ to microcentrifuge tubes containing $150 \mu \mathrm{l} 100 \mathrm{mg}$ unlabelled methionine $\mathrm{ml}^{-1}$. Cells were pelleted by centrifugation and washed with $1 \mathrm{ml}$ cold $\mathrm{H}_{2} \mathrm{O}$, pelleted again and the supernatant removed. Tubes were placed on ice until extracted.

Protein extraction and separation. Cells were broken by vortexing in the presence of glass beads and proteins extracted according to the method outlined by McAlister et al. (1979). Samples were heated at $95^{\circ} \mathrm{C}$ for $2 \mathrm{~min}$ to ensure complete protein denaturation and frozen until required. Protein concentration in the extracts was determined according to Bradford (1976). Proteins were separated on SDS-polyacrylamide gels using the general technique outlined by Laemmli (1970). Stacking and separating gel concentrations were $4 \%$ and $10 \%$, respectively. Thawed protein samples were loaded onto the gel to give $10 \mu \mathrm{g}$ protein per lane and run against low range molecular mass standards (Bio-Rad). Gels were silver-stained, fixed with $5 \%(\mathrm{v} / \mathrm{v})$ acetic acid, immersed in Amplify (Amersham) and dried. The dried gels were exposed to Hyperfilm-MP (Amersham) at $-70^{\circ} \mathrm{C}$ for $4-5 \mathrm{~d}$ before developing.

Stress resistance. To avoid the effects of salt and cycloheximide in cultures while being stressed, all samples were centrifuged 
(1500 $\mathrm{g}$ for $2 \mathrm{~min}$ ) and cells resuspended in the same volume of YEP with no glucose (YEPNG). Thermotolerance was measured by transferring a $4.1 \mathrm{ml}$ aliquot of resuspended cells to a $22 \mathrm{~mm}$ Pyrex test tube and heating at $60^{\circ} \mathrm{C}$ for $30 \mathrm{~s}$, rapidly raising the temperature to $52{ }^{\circ} \mathrm{C}$. The tube was then transferred to an oscillating water bath at $52{ }^{\circ} \mathrm{C}$ for $4.5 \mathrm{~min}$, before being cooled in ice water to $25^{\circ} \mathrm{C}$. Freeze-thaw resistance was measured by transferring a $1 \mathrm{ml}$ aliquot of the resuspended cells into a $1.5 \mathrm{ml}$ microcentrifuge tube and submerging in liquid nitrogen for $5 \mathrm{~min}$ (cooling rate approximately $200^{\circ} \mathrm{C} \mathrm{min}^{-1}$ ). The tube was subsequently thawed for $4-5 \mathrm{~min}$ in a $25^{\circ} \mathrm{C}$ water bath (warming rate approximately $190^{\circ} \mathrm{C} \mathrm{min}{ }^{-1}$ ). For heat and freeze-thaw stress, viable count of survivors was determined by plating suitable dilutions onto YEP agar (1\% glucose) and incubating at $28{ }^{\circ} \mathrm{C}$ for $24-48 \mathrm{~h}$. Osmotolerance of cells was determined by the use of $0.1 \mathrm{ml}$ pour plates in YEP $(1 \%$ glucose) containing $1.5 \mathrm{M} \mathrm{NaCl}$. Plates were incubated at $28{ }^{\circ} \mathrm{C}$ for 7-10 d before counting.

Trehalose and glycerol determination. Samples for trehalose and glycerol analyses were taken after resuspension of cells for stress testing. Trehalose was extracted from chilled and washed cells with $0.5 \mathrm{M}$ trichloroacetic acid and estimated by the anthrone method as previously described (Lewis et al., 1993a). Glycerol was extracted according to the method described by Blomberg et al. (1988) and analysed enzymically using a test kit (Boehringer).

\section{RESULTS}

To isolate the effects of hsps from trehalose and other factors during heat and salt shock, cycloheximide was used to block cytoplasmic protein synthesis (Schindler \& Davies, 1975). Measurement of $\left[{ }^{14} \mathrm{C}\right]$ leucine incorporation into protein in the presence of cycloheximide showed that as little as $5 \mu \mathrm{g} \mathrm{ml}^{-1}$ severely repressed protein synthesis and a concentration of $10 \mu \mathrm{g} \mathrm{ml}^{-1}$ appeared to block protein synthesis almost entirely (results not shown). To ensure that protein synthesis was completely blocked, 20-50 $\mu \mathrm{g}$ cycloheximide $\mathrm{ml}^{-1}$ was used for all subsequent experiments. Its efficacy was confirmed by the pattern of protein synthesis presented in Fig. 1 (lanes $\mathrm{c}$ and e) where cells treated with $20 \mu \mathrm{g}$ cycloheximide $\mathrm{ml}^{-1}$ showed no protein synthesis during heat or salt shock.

To investigate the role of trehalose and hsps in induced stress tolerance, respirofermentative cells of strain A9 were heat-shocked in the presence or absence of cycloheximide. Hsp synthesis, trehalose accumulation and induced stress tolerance were assessed. A number of proteins showed increased synthesis during heat shock compared with control cells, with bands evident at approximately 63.5, 69, 72, 74, 86, 87 and $100 \mathrm{kDa}$ (Fig. 1, lane b). In contrast, those cells treated with cycloheximide showed no protein synthesis during heat shock (Fig. 1, lane c). Cells heat-shocked in the absence of cycloheximide accumulated trehalose to $5-8 \%$ (w/w dry cell wt) compared with less than $0.5 \%$ for non-heat-shocked control cells. However, when protein synthesis was blocked by the addition of cycloheximide, trehalose accumulation was only $30-60 \%$ of that induced in the absence of cycloheximide. The level of cycloheximide $\left(5 \mu \mathrm{g} \mathrm{ml}^{-1}\right)$ required to inhibit trehalose accumulation was similar to that required to severely restrict protein

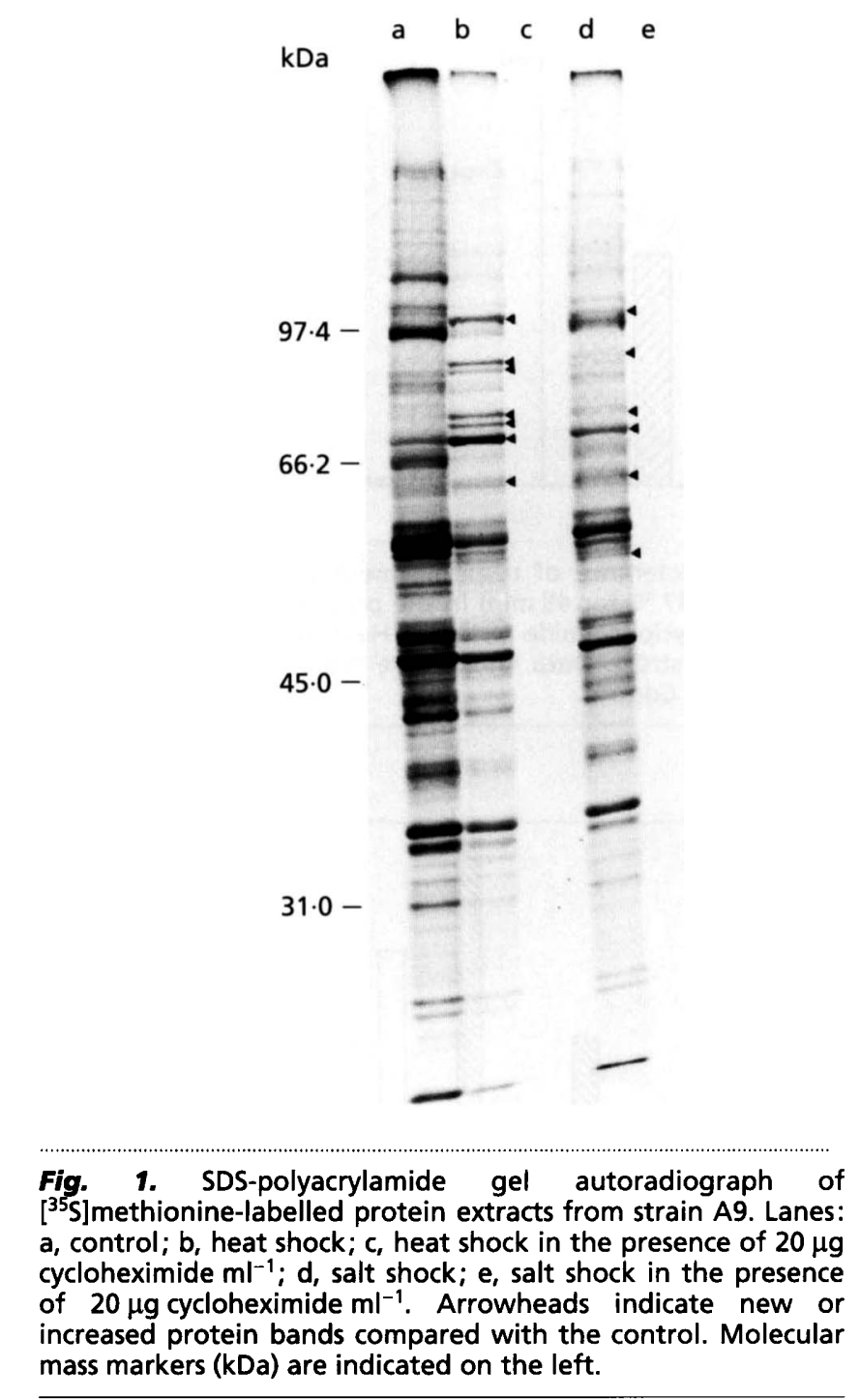

synthesis (data not shown). Above this level an increase in the concentration of cycloheximide did not lead to further inhibition of trehalose accumulation.

Stress tolerance results are presented in Fig. 2. Control cells which were not heat-shocked showed typical sensitivity to the stresses. Heat and freezing stress induced extremely high mortality (less than $0.0001 \%$ survivors), although salt tolerance was greater (approximately $0 \cdot 1 \%$ survivors). Cells heat-shocked in the absence of cycloheximide all showed large increases in stress tolerance. This included salt tolerance, a phenomenon which has not previously been shown to occur in yeast. Thermotolerance and salt tolerance increased approximately 1000 fold and freezing tolerance approximately 10000 -fold. For cells heat-shocked in the presence of cycloheximide, heat and salt tolerance was still induced, although at lower levels than in the absence of cycloheximide. However, freezing tolerance was not induced. This observation was true for all experiments where protein synthesis was blocked during heat shock, which may imply that hsps are 


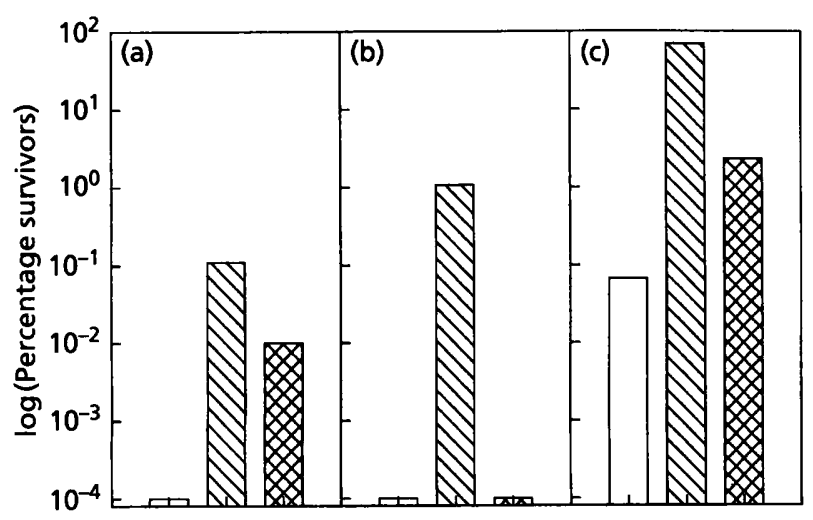

Fig. 2. Stress tolerance of respirofermentative phase $A 9$ cells heat-shocked $\left(37^{\circ} \mathrm{C}\right.$ for $45 \mathrm{~min}$ ) in the presence $(\otimes)$ or absence ( $\mathbb{})$ of $50 \mu \mathrm{g}$ cycloheximide $\mathrm{ml}^{-1}$. (a) Heat stress, (b) freezing stress, (c) salt stress. Data shown are from a representative experiment. $\square$, Control.

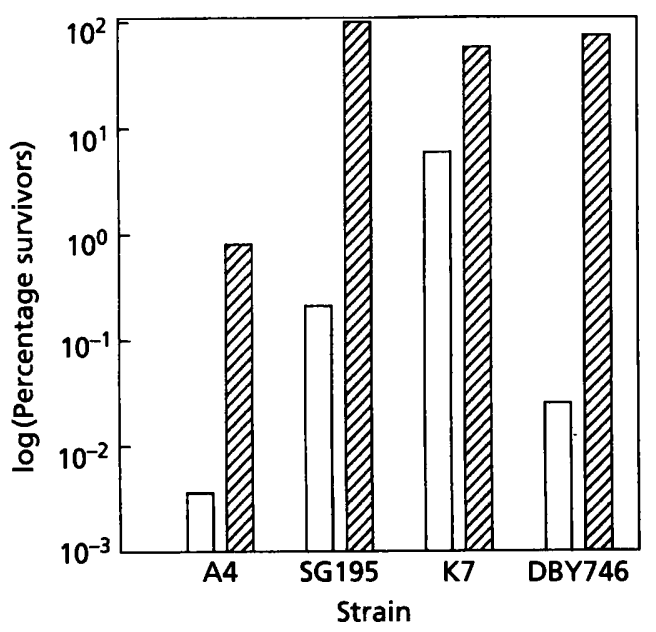

Fig. 3. Induction of salt tolerance by heat shock in four strains of $S$. cerevisiae. Respirofermentative phase cells were heatshocked $\left(37^{\circ} \mathrm{C}\right.$ for $\left.45 \mathrm{~min}\right)$ and subjected to salt stress. Data are means of duplicate experiments. $\square$, Control; $\square$, heat shock.

essential for induced tolerance to rapid freezing. In the case of heat and salt stress, however, protein synthesis does not appear to be essential for induction of tolerance, although over 10 -fold higher levels of tolerance were induced when protein synthesis was not blocked.

As the observation of induction of salt tolerance by heat shock has not been previously reported in detail and other workers have produced negative results, the experiment was repeated using several other strains of $S$. cerevisiae including the laboratory strain DBY746 and the sake strain $\mathrm{K} 7$ (Fig. 3). For all strains tested, salt tolerance could be induced in respirofermentative phase cells by heat shock. The intrinsic tolerance of the strains varied greatly, but in all cases the magnitude of stress tolerance induction was large, ranging from 10-fold for strain K7

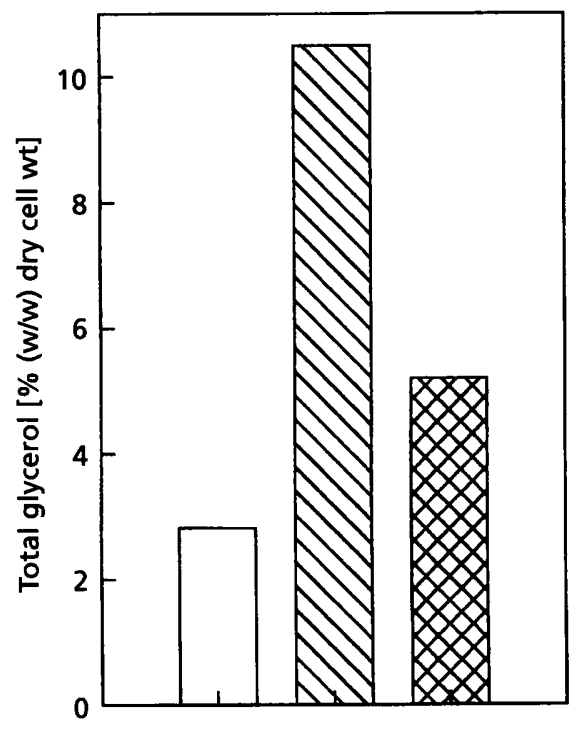

Fig. 4. Accumulation of glcerol in respirofermentative phase $A 9$ cells during salt shock $(0.3 \mathrm{M} \mathrm{NaCl}$ for $45 \mathrm{~min})$ in the presence $(\otimes)$ or absence $(\mathbb{\nabla})$ of $20 \mu \mathrm{g}$ cycloheximide $\mathrm{ml}^{-1}$. Data shown are from a representative experiment. $\square$, Control.

which had a high level of intrinsic tolerance, to 3000-fold for strain DBY746 which was intrinsically very sensitive. The method used to assess salt tolerance was slightly different to that employed by Trollmo et al. (1988) who reported negative results for very similar experiments. In their experiments, spread plates were employed rather than pour plates, which were used here. To confirm the results obtained here, the experiment was further repeated using spread plates. Results using strain A9 showed that salt tolerance following heat shock was induced equally for both spread and pour plates (results not shown).

As another way to examine the contribution of accumulated solutes and stress proteins to induced stress tolerance, parallel experiments were performed using salt shock instead of heat shock. Salt shock induced the synthesis of a number of stress proteins, some of which appear to overlap with those induced by heat shock (Fig. 1 , lane d). Bands were evident at $63 \cdot 5,69,86$ and $100 \mathrm{kDa}$, corresponding to the heat shock induced bands, as well as at 53.5 and $71 \mathrm{kDa}$, which were induced only by salt shock. As for the heat shocked cells, the presence of cycloheximide completely inhibited protein synthesis during salt shock (Fig. 1, lane e).

The synthesis of glycerol during salt shock in the presence or absence of cycloheximide is shown in Fig. 4. As for trehalose accumulation induced by heat shock, glycerol synthesis was substantially reduced in the presence of cycloheximide. To ensure that there was no overlap in induction of trehalose and glycerol by heat and salt shock, respectively, time course experiments for each shock were performed. Results show that heat shock induced the accumulation of trehalose but not glycerol, while salt shock led to the accumulation of glycerol but not trehalose, implying that there is no overlap in the 

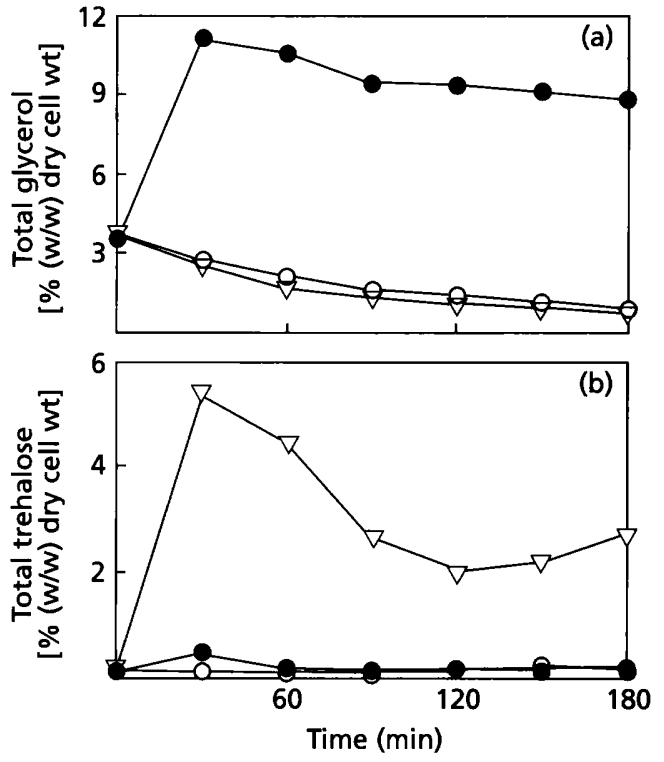

Fig. 5. Accumulation of solutes during extended exposure to heat and salt shock conditions. Respirofermentative phase cells of strain A9 were subjected to heat $\left(37^{\circ} \mathrm{C}, \nabla\right)$ or salt $(0.3 \mathrm{M}$ $\mathrm{NaCl}, 0$ ) shock and assayed for glycerol (a) and trehalose (b). $\mathrm{O}$. Control cells. Data are means of duplicate experiments.

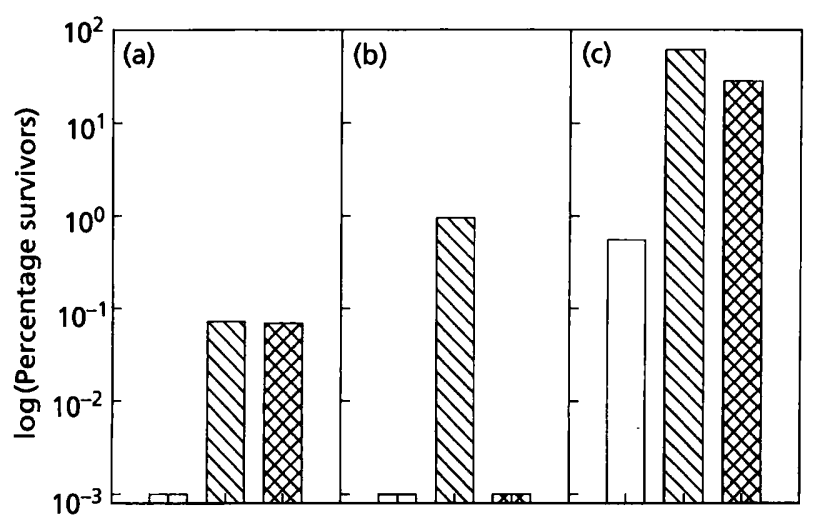

Fig. 6. Stress tolerance of respirofermentative phase A9 cells salt-shocked $(0.3 \mathrm{M} \mathrm{NaCl}$ for $45 \mathrm{~min})$ in the presence $(\otimes)$ or absence $(\mathbb{\nabla})$ of $20 \mu \mathrm{g}$ cycloheximide $\mathrm{ml}^{-1}$. (a) Heat stress, (b) freezing stress, (c) salt stress. Data shown are from a representative experiment. $\square$, Control.

mechanisms which induce the accumulation of these two solutes (Fig. 5).

The stress tolerance of salt-shocked cells showed similarities to the response induced by heat shock (Fig. 6). Control cells again showed acute sensitivity to all stresses while cells salt shocked in the absence of cycloheximide showed increased tolerance to all stresses, including heat and freezing stress as well as salt stress. Heat tolerance increased approximately 100 -fold, freezing tolerance by 1000 -fold and salt tolerance by 100 -fold. Cells salt-shocked in the presence of cycloheximide showed a slightly different response (Fig. 6). While heat tolerance was unchanged in the absence of protein synthesis, induction of salt tolerance was approximately halved. This was a small decrease compared to the control but was consistent in all experiments. Induction of increased tolerance to rapid freezing was completely blocked. As for heat shock, this appears to indicate that protein synthesis is essential for induced tolerance to freezing stress but not for induced tolerance to heat and salt stress.

\section{DISCUSSION}

Results demonstrating induction of thermotolerance by heat shock (Fig. 2) are in agreement with previously published work (McAlister \& Finkelstein, 1980; Watson et al., 1984; Hottiger et al., 1987, 1989; Panek et al., 1990; De Virgilio et al., 1991). Induction of thermotolerance was rapid and of large magnitude, generally about 1000fold for respirofermentative phase cells (Fig. 2a). In addition, thermotolerance could be induced, although at reduced levels, despite the inhibition of protein synthesis during heat shock (Figs 1 and 2a). This has also been previously reported in work where protein synthesis was inhibited either by the use of cycloheximide (Hall, 1983; Watson et al., 1984; De Virgilio et al., 1990) or temperature-sensitive protein synthesis mutants (De Virgilio et al., 1991). These results appear to imply that protein synthesis is not essential for induction of thermotolerance, suggesting that, while hsps appear almost certain to be involved, other factors may also have a role.

While a number of other factors including antioxidant enzymes and plasma membrane A TPase (Piper, 1993) may be involved with heat-shock-induced stress tolerance, trehalose still appears likely to be a major factor in $S$. cerevisiae. It may act as a stress protectant for two reasons. Firstly, trehalose has been shown to protect membranes and proteins from stress in vitro (Crowe et al., 1992) and secondly, its accumulation and depletion has been closely correlated with changes in induced thermotolerance in yeast (Hottiger et al., 1987, 1989; De Virgilio et al., 1990, 1991). As a consequence, it has been suggested that induction of heat tolerance by heat shock in the absence of protein synthesis is the result of the thermoprotective effect of trehalose (Hottiger et al., 1989; De Virgilio et al., $1990,1991)$. If this were the case, it follows that similar results should be found for cells which have elevated levels of other solutes which may protect proteins and membranes from stress. An examination of cells which have been subjected to salt stress appeared to confirm this. When stress tolerance induced by salt shock was examined (Fig. 6) thermotolerance was increased in the presence or absence of protein synthesis, just as in the case of heat shock (Fig. 2a). While salt shock did induce the increased synthesis of some proteins which were also induced by heat shock, notably proteins at $63 \cdot 5,69,87$ and $100 \mathrm{kDa}$ (Fig. 1), the same level of thermotolerance was apparent in the cells with or without protein synthesis, implying that increased hsp synthesis was not necessary for saltshock-induced thermotolerance (Fig. 6). Glycerol is 
similar to trehalose in many ways, being a polyhydroxy compound which may be accumulated to very high levels in yeast cells without toxic or inhibitory effects (Brown, 1990). It has also been implicated in the thermoprotection of proteins (Back et al., 1979; Henle et al., 1982; Kim \& Lee, 1993) and whole cells (Henle et al., 1982). In both heat and salt shock, substantial thermotolerance may be induced without the synthesis of hsps, and in both cases the cells accumulate solutes which have previously been associated with the protection of cells from heat stress. These results imply that trehalose and glycerol may act as thermoprotectants under conditions of heat shock and salt shock, respectively.

Unlike heat, however, induced freezing tolerance appears to rely heavily on protein synthesis. Both heat and salt shock were able to induce tolerance to rapid freezing in respirofermentative phase cells, increasing the tolerance of the cells 1000- to 10000-fold (Figs $2 \mathrm{~b}$ and 6b). However, when hsp synthesis was blocked by the addition of cycloheximide during heat or salt shock, no increase in tolerance was induced (Figs $2 \mathrm{~b}$ and $6 \mathrm{~b}$ ). These results may imply that hsp synthesis is vital for the protection of cells from rapid freezing and that the presence of solutes such as trehalose and glycerol are of no benefit. Although the accumulation of solutes such as trehalose and glycerol may act to protect cells from slow freezing stress (Coutinho et al., 1988; Karow, 1991), we have previously shown that neither trehalose nor glycerol is able to provide protection from rapid freezing (Lewis et al., 1994). While it may be proposed that induced tolerance to rapid freezing is largely the result of hsp synthesis, the mechanism by which hsps might act is not clear. Komatsu et al. (1990) drew on the known functions of hsps to hypothesize that they might provide general macromolecular stabilization during freezing. It is also possible that the presence of hsps in the cell immediately after the stress (i.e. once the cell is thawed) may increase viability by enabling the cell to begin repair processes rapidly.

Although induction of osmotolerance by salt shock has been reported (Trollmo et al., 1988; Varela et al., 1992; Blomberg \& Adler, 1993), its induction by heat shock has not (Trollmo et al., 1988; Varela et al., 1992). In this study, heat shock induced large increases in salt tolerance for strain A9 (Fig. 2c) and four other strains of S. cerevisiae including industrial and laboratory strains (Fig. 3). This induction was reduced by the presence of cycloheximide during heat shock, but was still substantial, implying that hsps are not vital for induced tolerance to salt stress (Fig. 2c). This situation appears very similar to that for induced heat tolerance, where hsps are likely to have some involvement but are not obligatory for stress tolerance. In the case of salt tolerance, trehalose has been demonstrated to have a protective effect on yeast cells (Mackenzie et al., 1988; D'Amore et al., 1991), possibly by acting as a compatible solute during dehydration (Brown, 1990), or acting to stabilize membranes and proteins (Crowe et al., 1992). Another possible explanation is that trehalose may act as an energy or reserve carbohydrate source to enable the restoration of turgor pressure after the initial dehydration of the cell which occurs when yeast is exposed to salt stress (Brown, 1990). Trehalose may act as a readily convertible energy source to enable the transport of glucose into the cell and its conversion to glycerol, or as a reserve carbohydrate which may itself be readily converted into glycerol. A third possibility is that accumulated trehalose may stabilize cell membrane or protein structure during cell dehydration. It may also be possible that a combination of these effects occurs.

Induction of salt tolerance by heat shock, however, is at odds with previously published observations (Trollmo $e t$ al., 1988; Varela et al., 1992). Experiments performed in work presented here were very similar to those performed by Trollmo et al. (1988) except for the method of exposing the cells to the high salt agar which acted as the stress. Trollmo et al. (1988) used $0 \cdot 1 \mathrm{ml}$ culture samples on spread plates to assess salt tolerance after heat shock, while in the present work $0.1 \mathrm{ml}$ culture samples in pour plates were employed. Using the pour plate method, both control and heat shocked cells are briefly exposed to heat stress $\left(45-47^{\circ} \mathrm{C}\right)$ while being mixed with the molten agar during the making of the plates, a stress which is not experienced by cells during the making of spread plates. Thus it was possible that the increased viable count in the heat-shocked samples was a result of the increased thermotolerance of the heat-shocked cells rather than increased salt tolerance. However, in an experiment where parallel pour and spread plates were prepared, similarly increased viable counts were evident on both sets of plates, confirming that the effect was the result of increased salt tolerance rather than thermotolerance. Experiments were also performed to confirm that the phenomenon was not confined to one strain, and all strains tested demonstrated increased salt tolerance after heat shock (Fig. 3).

In the light of these findings, explanation of the discrepancy between results presented here and those of Trollmo et al. (1988) and Varela et al. (1992) is difficult. One possibility is simply that the strain of yeast used in the work of Trollmo et al. (1988) did not behave physiologically in the same way as the strains employed in work presented here. For example, the strain may not have accumulated significant levels of trehalose upon heat shock, and if the present explanation of the phenomenon is correct this would preclude it from exhibiting increased salt tolerance. In the work of Varela et al. (1992), cells were heat-shocked and then methionine uptake and incorporation into protein in the presence of $1.4 \mathrm{M} \mathrm{NaCl}$ was measured. Cells which were preconditioned by exposure to salt shock demonstrated higher rates of methionine uptake and incorporation than control cells, indicating that the salt shock had protected the cells from the $1.4 \mathrm{M} \mathrm{NaCl}$ stress. Heat-shocked and control cells demonstrated equivalent levels of methionine uptake in the presence of $1.4 \mathrm{M} \mathrm{NaCl}$, indicating that heat shock had no protective effect on the cells. However, the rate of incorporation of the methionine into proteins during salt stress recovered more quickly in heat-shocked cells than control cells, implying that prior heat shock had provided some protection of the protein biosynthetic machinery. In addition, the experiments only considered cellular metabolism over a period of $3 \mathrm{~h}$ rather than the ability to grow 
and reproduce, and it is possible, for example, that heatshocked cells could sustain equivalent damage when subjected to stress as non-heat-shocked cells, yet have a greater ability to recovery and survive. This has been recently shown in heat stressed $S$. cerevisiae cells, where ultrastructural damage for control and heat-shocked cells was similar, but heat-shocked cells were able to recover and recommence growth far more quickly than the control cells (Webster \& Watson, 1993).

The level of trehalose accumulated in cells under heat shock conditions was depressed in the presence of cycloheximide implying that protein synthesis is essential for maximum trehalose accumulation. When cells were heat-shocked in the presence of various concentrations of cycloheximide, a similar concentration $\left(5 \mu \mathrm{g} \mathrm{m}^{-\mathbf{1}}\right)$ was required to cause maximum inhibition of trehalose accumulation as was required to block protein synthesis. If the concentration of cycloheximide was increased above this level, no further reduction in the accumulation of trehalose was evident. The accumulation in the absence of protein synthesis is suggested to be the result of changes in enzyme kinetics under heat shock conditions, a process which is unaffected by the absence of protein synthesis (Neves \& Francois, 1992). These results confirm previously published reports of the ability of fungi to accumulate trehalose in the absence of protein synthesis, but that maximum accumulation occurs when protein synthesis is not inhibited (De Virgilio et al., 1990; Panek et al., 1990; Neves \& Francois, 1992).

Induction by salt shock of stress proteins with strong similarities to hsps has been demonstrated in a number of organisms, including cyanobacteria (Bhagwat \& Apte, 1989), B. subtilis (Volker et al., 1992) and plants (Harrington \& Alm, 1988). In S. cerevisiae, however, induction of hsps by salt shock has only recently been shown. Varela et al. (1992) demonstrated induction of a range of proteins by salt shock, including those with molecular masses of 14, 26, 29, 33, 35, 45, 63 and $73 \mathrm{kDa}$. While most of the induced proteins did not relate to conventional hsps, it was suggested that the 26 and $14 \mathrm{kDa}$ proteins corresponded to hsp26 and hsp12, respectively. In work presented here, heat shock of strain A9 induced increased synthesis of proteins at $63 \cdot 5,69,72$, $74,86,87$ and $100 \mathrm{kDa}$. Salt shock induced proteins were detected at 53.5, 63.5, 69, 71, 87 and $100 \mathrm{kDa}$, implying an overlap in the proteins induced by heat and salt shock. Some of these proteins may also correspond with heat shock induced hsps previously documented for yeast, but two bands $(53.5$ and $71 \mathrm{kDa}$ ) were induced by salt shock and not by heat shock. These bands may correspond to enzymes associated with the synthesis of glycerol which have been shown to increase in cells exposed to osmotic shock (Varela et al., 1992; Blomberg \& Adler, 1993). While there is some overlap in the proteins induced by salt shock in the present work $(63.5$ and $71 \mathrm{kDa})$ and that of Varela et al. (1992) (63 and $73 \mathrm{kDa}$ ), many of the proteins are different. This may be due to differences between yeast strains, but may also be a result of the different severity of the shock conditions employed. While the work presented here employed a salt shock concentration of $0.3 \mathrm{M} \mathrm{NaCl}$,
Varela et al. (1992) employed a concentration of $0.7 \mathrm{M}$ $\mathrm{NaCl}$, a significantly greater stress. In addition, hsp26 which was detected by Varela et al. (1992) would be difficult to detect by the methods used in the present work (which relied on the incorporation of methionine and cysteine) since hsp26 contains no methionine and only very low levels of cysteine (Bossier et al., 1989). Nevertheless, work presented here showed that hsps were induced by heat and salt shock and that there is some overlap in the proteins synthesized.

In summary, results presented here demonstrate that physiological shock may induce increased tolerance of heat and salt stress in the absence of protein synthesis, and indicate that tolerance may be associated with the accumulation of polyols such as trehalose and glycerol. However, induction of tolerance to rapid freezing appears to rely on the ability to synthesize proteins, implying that hsps may be an important factor in induced cryotolerance.

\section{ACKNOWLEDGEMENTS}

This work was supported by an Australian Postgraduate Research Award, Industry (J.G.L.) and University of New England internal research grants. We thank Claudia Gross for assistance in running the protein gels.

\section{REFERENCES}

Attfield, P. V. (1987). Trehalose accumulates in Saccharomyces cerevisiae during exposure to agents that induce heat shock response. FEBS Lett 225, 259-263.

Back, J. F., Oakenfull, D. \& Smith, M. B. (1979). Increased thermal stability of proteins in the presence of sugars and polyols. Biochemistry 18, 5191-5196.

Bhagwat, A. A. \& Apte, S. K. (1989). Comparative analysis of proteins induced by heat shock, salinity, and osmotic stress in the nitrogen-fixing cyanobacterium Anabaena sp. strain L-31. J Bacteriol 171, 5187-5189.

Blomberg, A. \& Adler, L. (1993). Tolerance of fungi to $\mathrm{NaCl}$. In Stress Tolerance of Fungi, pp. 209-231. Edited by D. H. Jennings. New York: Marcel Dekker.

Blomberg, A., Larsson, C. \& Gustafsson, L. (1988). Microcalorimetric monitoring of growth of Saccharomyces cerevisiae: osmotolerance in relation to physiological state. J Bacteriol 170, 4562-4568.

Bossier, P., Fitch, I. T., Boucherie, H. \& Tuite, M. F. (1989). Structure and expression of a yeast gene encoding the small heatshock protein hsp26. Gene 78, 323-330.

Bradford, M. (1976). A rapid and sensitive method for the quantitation of microgram quantities of protein utilizing the principle of protein-dye binding. Anal Biochem 72, 248-254.

Brown, A. D. (1990). Microbial Water Stress Pbysiology. Chichester: Wiley.

Coutinho, C., Bernardes, E., Felix, D. \& Panek, A. D. (1988). Trehalose as a cryoprotectant for preservation of yeast strains. $J$ Biotechnol 7, 23-32.

Craig, E. A., Gambill, B. D. \& Nelson, R. J. (1993). Heat shock proteins: molecular chaperones of protein biogenesis. Microbiol Rev 57, 402-414.

Crowe, J. H., Hoekstra, F. A. \& Crowe, L. M. (1992). Anhydrobiosis. Annu Rev Physiol 54, 579-599. 
D'Amore, T., Crumplen, R. \& Stewart, G. G. (1991). The involvement of trehalose in yeast stress tolerance. J Ind Microbiol 7, 191-196.

De Virgilio, C., Simmen, U., Hottiger, T., Boller, T. \& Wiemken, A. (1990). Heat shock induces enzymes of trehalose metabolism, trehalose accumulation, and thermotolerance in Scbizosaccharomyces pombe, even in the presence of cycloheximide. FEBS Lett 273, 107-110.

De Virgilio, C., Piper, P., Boller, T. \& Wiemken, A. (1991). Acquisition of thermotolerance in Saccharomyces cerevisiae without heat shock protein hsp104 and in the absence of protein synthesis. FEBS Lett 288, 86-90.

Hall, B. G. (1983). Yeast thermotolerance does not require protein synthesis. J Bacteriol 156, 1363-1365.

Harrington, H. M. \& Alm, D. M. (1988). Interaction of heat and salt shock in cultured tobacco cells. Plant Physiol 88, 618-625.

Henle, K. J., Nagle, W. A., Moss, A. J. \& Herman, T. S. (1982). Polyhydroxy compounds and thermotolerance: a proposed concatenation. Radiat Res 92, 445-451.

Hottiger, T., Boller, T. \& Wiemken, A. (1987). Rapid changes of heat and desiccation tolerance with changes of trehalose content in Saccharomyces cerevisiae cells subjected to temperature shifts. FEBS Lett 220, 113-115.

Hottiger, T., Boller, T. \& Wiemken, A. (1989). Correlation of trehalose content and heat resistance in yeast mutants altered in the RAS/adenylate cyclase pathway: is trehalose a thermoprotectant? FEBS Lett 255, 431-434

Hottiger, T., De Virgilio, C., Bell, W., Boller, T. \& Wiemken, A. (1992). The 70-kilodalton heat-shock proteins of the SSA subfamily negatively modulate heat-shock-induced accumulation of trehalose and promote recovery from heat stress in the yeast, Saccharomyces cerevisiae. Eur J Biochem 210, 125-132.

Karow, A. M. (1991). Chemical cryoprotection of metazoan cells. Bioscience 41, 155-160.

Kim, D. \& Lee, Y. J. (1993). Effect of glycerol on protein aggregation: quantitation of thermal aggregation of proteins from $\mathrm{CHO}$ cells and analysis of aggregated proteins. $J$ Therm Biol 18 , 41-48.

Komatsu, Y., Kaul, S. C., Iwahashi, H. \& Obuchi, K. (1990). Do heat shock proteins provide protection against freezing? FEMS Microbiol Lett 72, 159-162.

Laemmli, U. K. (1970). Cleavage of structural proteins during assembly of the head of bacteriophage T4. Nature 227, 680-685.

Lewis, J. G., Learmonth, R. P. \& Watson, K. (1993a). The role of growth phase and ethanol in freeze-thaw stress resistance of Saccharomyces cerevisiae. Appl Environ Microbiol 59, 1065-1071.

Lewis, J. G., Northcott, C. J., Learmonth, R. P., Attfield, P. V. \& Watson, K. (1993b). The need for consistent nomenclature and assessment of growth phases in diauxic cultures of Saccharomyces cerevisiae. J Gen Microbiol 139, 835-839.

Lewis, J. G., Learmonth, R. P. \& Watson, K. (1994). Cryoprotection of yeast by alcohols during rapid freezing. Cryobiology 31, 193-198.
Lindquist, S. \& Craig, E. A. (1988). The heat shock proteins. Annu Rev Genet 22, 631-677.

McAlister, L. \& Finkelstein, D. B. (1980). Heat shock proteins and thermal resistance in yeast. Biochem Biopbys Res Commun 3, 819-824.

McAlister, L., Strausberg, S., Kulaga, A. \& Finkelstein, D. B. (1979). Altered patterns of protein synthesis induced by heat shock of yeast. Curr Genet 1, 63-74.

Mackenzie, K. F., Singh, K. K. \& Brown, A. D. (1988). Water stress plating hypersensitivity of yeasts: protective role of trehalose in Saccharomyces cerevisiae. J Gen Microbiol 134, 1661-1666.

Neves, M.-J. \& Francois, J. (1992). On the mechanism by which a heat shock induces trehalose accumulation in Saccharomyces cerevisiae. Biochem J 288, 859-864.

Panek, A. C., Vania, J. J. M., Paschoalin, M. F. \& Panek, D. (1990). Regulation of trehalose metabolism in Saccharomyces cerevisiae mutants during temperature shifts. Biocbimie 72, 77-79.

Piper, P. W. (1993). Molecular events associated with acquisition of heat tolerance by the yeast Saccharomyces cerevisiae. FEMS Microbiol Rev 11, 339-356.

Sanchez, Y. \& Lindquist, S. L. (1990). HSP104 required for induced thermotolerance. Science 248, 1112-1115.

Sanchez, Y., Taulien, J., Borkovich, K. A. \& Lindquist, S. (1992). Hsp104 is required for tolerance to many forms of stress. EMBO J 11, 2357-2364.

Schindler, D. \& Davies, J. (1975). Inhibitors of macromolecular synthesis in yeast. Methods Cell Biol 12, 17-38.

Smith, B. J. \& Yaffe, M. P. (1991). Uncoupling thermotolerance from the induction of heat shock proteins. Proc Natl Acad Sci USA 88, 11091-11094.

Trollmo, C., Andre, L., Blomberg, A. \& Adler, L. (1988). Physiological overlap between osmotolerance and thermotolerance in Saccharomyces cerevisiae. FEMS Microbiol Lett 56, 321-326.

Varela, J. C. S., Van Beekvelt, C., Planta, R. J. \& Mager, W. H. (1992). Osmostress-induced changes in yeast gene expression. Mol Microbiol 6, 2183-2190.

Volker, U., Mach, H., Schmid, R. \& Hecker, M. (1992). Stress proteins and cross-protection by heat shock and salt stress in Bacillus subtilis. J Gen Microbiol 138, 2125-2135.

Watson, K. (1990). Microbial stress proteins. Adv Microb Pbysiol 31, 183-223.

Watson, K., Dunlop, G. \& Cavicchioli, R. (1984). Mitochondrial and cytoplasmic protein synthesis are not required for heat shock acquisition of ethanol and thermotolerance in yeast. FEBS Lett 172, 299-302.

Webster, D. L. \& Watson, K. (1993). Ultrastructural changes in yeast following heat shock and recovery. Yeast 9, 1165-1175.

Received 28 July 1994; revised 31 October 1994; accepted 7 November 1994. 